\title{
Using Role-Playing Simulations to Teach Quality Control in the Design of Medical Devices
}

\author{
J. Christopher Bouwmeester ${ }^{1}$, Vicki Komisar ${ }^{1,2}$, Arushri Swarup ${ }^{1,3}$ \\ ${ }^{1}$ Institute of Biomaterials and Biomedical Engineering, University of Toronto; ${ }^{2}$ Toronto Rehabilitation Institute - \\ University Health Network; ${ }^{3}$ The Hospital for Sick Children, Toronto \\ chris.bouwmeester@utoronto.ca,v.komisar@utoronto.ca, arushri.swarup@mail.utoronto.ca
}

\begin{abstract}
A simulation is used to facilitate cooperative and team-based learning to introduce concepts of human factors, risk analysis, and quality control applied to the design of medical devices. We further use a friendly game-based approach to simulate the dynamics between a customer, a regulatory agency, and competitive manufacturers. Students are divided into manufacturing teams/companies and teaching assistants act as the customer and regulator. To promote positive interdependence and individual accountability, each student within a company is assigned roles of CEO, inspector, marketer, and designer. The goal for each company is to design and produce as many eye patch medical devices as possible, which must be approved by the regulator, within a tight deadline. Products are evaluated by the customer, who decides what price to pay for each unit, at the end of production. The most successful company is determined by the greatest amount of money earned after two rounds of production and sales.
\end{abstract}

Keywords: Prototypes, Medical Device, Quality Control, Cooperative Learning

\section{INTRODUCTION}

In the Biomedical Engineering Minor Capstone Design course offered at the University of Toronto, multidisciplinary teams of students enrolled in the engineering and arts and science faculties work together for two semesters to 1) identify a health-related problem and 2) design and prototype solutions to the problem. In addition to creating a working solution, each team is required to evaluate it in the context of Health Canada and US Food and Drug Administration medical device regulations. One of the most important considerations is the quality control of medical devices and the standards required by these agencies. It is a challenge to introduce and teach these standards (e.g., ISO 13485 or FDA 21 CFR 820.30 ) in an engaging format that promotes learning. This is especially difficult as students enrolled in the course are unlikely to have experienced aspects of quality control in their professional experience year internship and will likely not progress with their team design projects to the point where quality control becomes obviously relevant in their design. Further, roughly half of the students in the class have academic backgrounds in Life Sciences (as opposed to engineering), and accordingly may not have interacted with formal quality control procedures or systems as part of their courses or professional experience. To address these challenges in a biomedical engineering context, this role-playing simulation builds on the game used to teach concepts and principles of Total Quality Management to undergraduate engineering students [1].

This activity was also used to emphasize that iterations of prototypes and testing are particularly important in the broader context of the capstone design course in which these students are enrolled. While this activity was not related directly to each team's project, it was chosen because it related aspects of quality control and management of medical device design (i.e., an eye patch) to a simple case study that even students with no background in engineering could understand.

In this paper, we describe the core content and execution of our quality control activity. We also share preliminary student feedback on their perception of learning.

\section{METHODS}

This activity starts with a preparation lecture on the fundamental principles of quality management related to medical devices. We emphasized the plan, do, study, act (PDSA) cycle of continuous improvement, which relates to ISO 9001 and verification and validation testing, which relates to FDA regulations regarding design controls and the safety and efficacy standards of ISO 13485. Aspects of quality management dynamics are also briefly covered to help students reflect on their experience after the completion of the game activity.

After fundamental principles are covered, approximately 30 minutes are devoted to preparing for the subsequent simulation activity. The objective (to produce as many eye patch medical devices as possible) and rules of the simulation are presented (see Appendix A) and companies are formed by randomly organizing teams. Of 
note, the instructions provided here are tailored for a class size of 16 students and 4 teams of 4 students. Adjustments can be made on increasing the team size by adding in extra roles but key roles are the:

1) CEO - who can interact with the instructor for rule clarifications

2) marketer - who interacts with the customer

3) inspector - who interacts with the regulator

During the remaining preparation time, each company is able to inspect the construction materials (e.g., felt sheets, elastic bands, string, cotton pads, glue guns, tape, etc.), ask for rule clarifications, and ideally create a preliminary design or production plan. The TAs (playing the role of customer and regulator) are also available during the preparatory lecture to answer questions that specified members of each company may have regarding customer expectations and regulatory requirements.

The information provided to each company is that the customer will evaluate the appeal of each batch of products produced by each company and determine the payment after each production round. The marketer of each company is encouraged to consult with the customer to understand what qualities each product should have. The TA playing the role of the customer will decide what qualities are important or what specific needs are to be fulfilled (e.g., shape, texture, weight, fits well under glasses, comfort, etc.). Privately, the TA is instructed to determine a baseline unit price they are willing to pay for each individual product (e.g., \$1/eye patch) and a penalty/reward system for poor/good quality (e.g., \pm 10 cents for good or poor quality).

To emphasize the role that regulatory agencies have on the quality of medical devices, each company is made aware that they will have to get approval from a regulator prior to selling their products. The TA playing the role of regulator will determine if devices are safe to use. Privately, the TA is instructed to exercise right to require more or less requirements depending on the potential risk of a proposed design. As a guideline, the general safety requirements for eyepatches could potentially be: no sharp corners or objects, a secure strap (eye patch does not fall off face), or that light is completely blocked from entering the eye.

During the design studio period, the rules are briefly reviewed and the simulation is started promptly. At the start of the quality control activity all companies should be ready for production. The instructor is responsible for directing the simulation and keeping on schedule during the design studio period. The simulation starts with 30 minutes given for the first round of production. During this time each company must show their design (e.g., sketch or preliminary product) to the regulator to receive approval to sell their product. At the end of the first round, each company must cease design and production activities. If a company does not have approval, it will not be allowed to sell to customers. Approximately 20 minutes is given to allow the customer to decide on quality and issue a total payment based on the number of eye patches produced. Companies are not allowed to actively "sell" their products and must simply provide their products to the customer. A summary of sales and each company's profit will be presented by the customer at the end of the sales round. After the sales period, all companies are given 10 minutes to reflect on their first round of sales. During their reflection they are encouraged to have internal meetings on how to improve their competitiveness but they are not allowed to conduct any production activities. After this reflection is completed, the second round of production is commenced. This round is given 20 minutes (30-mins total: 10 -min reflection +20 -min production). If a company changed their design substantially, they might be required to obtain a new certificate of approval from the TA acting as the regulator but if the same product is produced that already received approval, no intervention is necessary. The final round of sales is given approximately 20 minutes and when all products have been tallied the final numbers of each company's earnings will be presented and the most profitable company announced.

After the simulation activity, each student was required to submit answers to a debriefing assignment (see Appendix B) one week after the simulation. These questions were linked to the 6 aspects of quality management dynamics (i.e., leadership, customer satisfaction, employee involvement, continuous improvement, supplier partnership, and performance measurement) that were presented in the preparatory lecture.

\section{RESULTS AND DISCUSSION}

The questions answered by participants of this simulation activity were tracked. Students were asked to answer only 3 out of 6 questions related to quality management dynamics. 6 students (out of 16) participated in the activity but only 3 out of the 6 participants completed valid answers. Student feedback was invalidated when they decided to answer all 6 questions, instead of only answering 3 of the questions as instructed. For the 3 valid responses, the frequency with which questions were answered is shown in Table 1.

Table 1. Question topics that students, who participated in the simulation, chose to answer.

\begin{tabular}{|l|l|}
\hline Leadership & 2 \\
\hline Customer Satisfaction & 3 \\
\hline Employee Involvement & 1 \\
\hline Continuous Improvement & 1 \\
\hline Supplier Partnership & 0 \\
\hline Performance Measurement & 2 \\
\hline
\end{tabular}

All 16 students in the class still completed the debrief survey. The valid responses from the group of students who 
Proc. 2017 Canadian Engineering Education Association (CEEA17) Conf.

did not participate in the activity is added to the group of valid responses from participants and shown in Table 2.

Table 2. Question topics that all students chose to answer.

\begin{tabular}{|l|l|}
\hline Leadership & 6 \\
\hline Customer Satisfaction & 9 \\
\hline Employee Involvement & 4 \\
\hline Continuous Improvement & 1 \\
\hline Supplier Partnership & 3 \\
\hline Performance Measurement & 4 \\
\hline
\end{tabular}

We tracked student responses to gain insights on the aspects of quality management dynamics that students felt most comfortable answering. It could be hypothesized that if a student decided to answer a particular question, then they felt that they comprehended (from knowledge gained in either the simulation or lecture material) that aspect of quality management dynamics better than other aspects not answered. Therefore, one trend that appears in both Tables 1 and 2, is that students comprehend the aspect of customer satisfaction. This may be related to the emphasis, throughout the course, that is placed on talking to users. The other trend that appears in Tables 1 and 2, is that students may not comprehend aspects of continuous improvement. This may be related the fact that no team produced any devices during first round of production. The likely reason for this poor performance is that only 6 students attended the simulation activity and this disrupted the preparatory planning severely and resulted in companies comprised of 2 employees (instead of 4) that had a decreased capacity for production. Therefore, continuous improvement was not easily practiced in the simulation because no improvement was demonstrated.

The questionnaire given to students after completion of the prototyping challenge asked students if they thought that the activity was more effective at delivering information compared to a normal lecture format. Out of 6 responses: 1 strongly agreed, 2 agreed, and 2 disagreed. Representative comments from students who strongly agreed was:

"[Liked the] intearctiveness and how we were forced to apply the knowledge on the spot."

"Engage[ment] with the customer \& inspector (FDA) is iterated and the process makes more sense."

Representative comments from a student who disagreed was:

"Didn't really teach anything we couldn't get from a flow chart."

"Interactions between team and consumer/regulatory body was not an accurate enough reflection of how it would go for us."

\subsection{Limitations}

The data collected from this activity are very small and may not be representative of the larger population of students. In relation to the small sample size, the intended outcomes of this simulation were hampered severely by the very low attendance for this activity. The activity was organized so that 4 companies, comprised of 4 students each would participate. Due to the nature of the simulation, it was expected that some students would not be fully engaged or even absent and this would have obvious effects on the ability of companies to perform to their full potential during the simulation. However, the fact that nearly $63 \%$ of the class decided not to attend made the simulation difficult to run as intended for those that chose to attend. To reduce the risk of this happening again, the consideration of harsher penalties for absent attendance for such a key learning activity will be considered and adjustments in grade weighting will be made to emphasize the importance of this activity.

A confounding factor that may have influenced the results is the order that the questions are listed in the debrief assignment. The fact that leadership was listed first followed by customer satisfaction, etc. could have biased the responses of students to answer the first 3 questions instead of evaluating all the 6 questions equally. This confounding factor will be mitigated in the future by randomizing the order that the questions are listed.

The theme of this simulation was chosen to be easily understood by every student and not necessarily related to any team's broader capstone design project. Regardless, there were some comments that indicate that students don't like that this activity was not directly related to their project, for example:

"[The activity was] not related to our project."

To address this type of comment in the future, more emphasis will be placed on debriefing each company (and design team) by requiring them to reflect on how the learnings from this activity could be applied to their own design projects.

\section{CONCLUSIONS AND FUTURE WORK}

Quality control is a critical element of medical device design, though can be challenging to teach to a diverse audience in a fun and inviting way. Through this simulation, we have endeavored to actively engage our biomedical engineering capstone design students in fundamentals of quality control. There are positive signs that this simulation activity has the potential to support the importance of improving design through user testing. There are also indications that students agree that this type of hands-on activity is more effective than a lecture format. The major lesson that was learned from conducting this simulation was providing the proper motivation for students to participate. The alignment of importance needs

CEEA17; Paper 062

University of Toronto; June 4-7, $2017 \quad-3$ of $4-$ 
to be aligned with the proper weight in terms of overall grade percentage.

\subsection{Future Work}

Using the mantra of continual improvement in the context of quality management, future work will be done to analyze whether positive (e.g., giving bonus marks for participation or attributing a higher relative grade weight) or negative motivation (e.g., making attendance mandatory or not receiving participation grades) can be used more effectively to increase participation in this activity and what effects on student motivation either choice may have.

\section{APPENDIX A: PROTOTYPING CHALLENGE SURVEY}

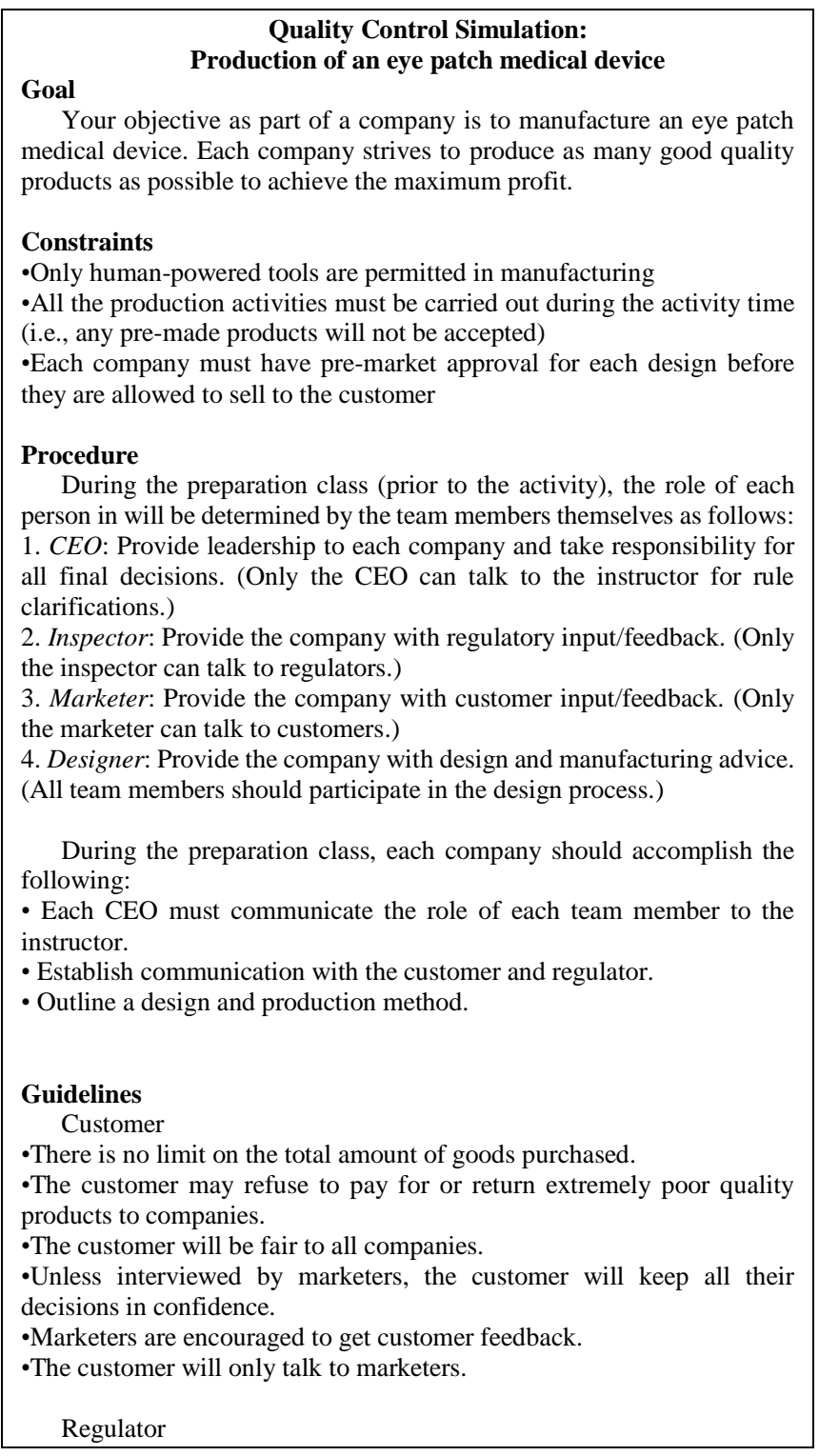

CEEA17; Paper 062

University of Toronto; June 4- 7, $2017 \quad-4$ of $4-$
- The regulator will grant pre-market approval (in the form of a certificate) for each new device design.

-The regulator will be fair to all companies but deliberate for as long as it sees fit for the sake of safety.

- The regulator will monitor the final sale of products to customers and may recall any devices that do not meet safety regulations

-The regulator will only talk to inspectors

\section{APPENDIX B: DEBRIEF QUESTIONS}

From your personal experiences as part of a company taking part in the quality control simulation activity, choose three of the following questions to answer:

1. Leadership: How did leadership (e.g., from the CEO specifically or the team generally) influence your team's success or failure?

2. Customer Satisfaction: How did your company ensure that the customer was satisfied? Is there anything you could have done to get better customer feedback?

3. Employee Involvement: Which company employee influenced product quality the most and why? How did the contributions (or lack of) of each employee contribute to success or failure?

4. Continuous Improvement: What did your company do to improve your device in the second round of production? Did your changes result in increased customer satisfaction?

5. Supplier Partnership: Were you limited by the raw materials supplied for the construction of your device? Is there anything you could have done to acquire better supplies or construction equipment?

6. Performance Measurement: How did you measure the performance of your product? Is there anything else that could have measured to improve overall quality?

\section{Acknowledgements}

The authors gratefully acknowledge financial support from the Canadian Institutes of Health Research Operating Grants (CIHR MOP 142178) (VK), the AGE-WELL Network of Centres of Excellence in Technology and Aging Graduate Student Scholarships (VK), and Toronto Rehabilitation Institute Graduate Student Scholarships (VK). VK also gratefullyf acknowledges funding from the University of Toronto's Institute of Biomaterials and Biomedical Engineering to present at CEEA 2017.

\section{References}

[1] Wang G. "Bringing games into the classroom in teaching quality control". Int $J$ Eng Educ 2004;20:678-89. 